\title{
Factors Associated that Explain Anxiety toward Mathematics on Undergraduate Students. (An Empirical Study in Tierra Blanca Veracruz-México)
}

\author{
Arturo, García-Santıllán \\ Full time Researcher in the Administrative-Economic Research Center, \\ Universidad Cristóbal Colón. Campus Calasanz. \\ Email: arturogarciasantillan@yahoo.com.mx
}

María del Socorro, Flóres-Serrano

First year student doctoral program in Management Sciences,

Universidad Cristóbal Colón, Veracruz, México

Email: er_211312@hotmail.com

José Satsumi, López-Morales

Third year student doctoral program in Management Sciences, Universidad Cristóbal Colón, Veracruz, México Email: jsatsumi@gmail.com

Lucía, Rıos- Alvarez

Liaison Officer to Mexico, School of Values for the Sustainable Development at UNESCO Email: lurioal@doctor.upv.es

\section{Doi:10.5901/mjss.2014.v5n15p483}

\section{Abstract}

The aim of study was to measure students' anxiety toward mathematics. We utilized a Muñoz and Mato scale. Was surveyed 437 students face to face in the Instituto Tecnológico de Tierra Blanca, Veracruz, México. The statistical procedure utilized was the Factorial analysis with extraction of components. Statistics test to prove: X2, Bartlett test of Sphericity, KMO (Kaiser-MeyerOlkin), MSA (Measure sampling adequacy) and Significance level: $p<0.05$ The results obtained from the Bartlett test of Sphericity KMO (0.881), X2 1758.251 with 10 df sig. 0.000 p< 0.01, MSA (ANSIEVAL 0.856a; ANSITEM 0.861a; ANSICOM 0.900a; ANSINUM 0.880a; ANSISIMA 0.942a) this means that the test Mato \& Muñoz help us to understand the mathematics anxiety on undergraduate students.

Keywords: Anxiety toward Mathematics, mathematics abilities, temporality toward mathematics, evaluation toward mathematics.

\section{Introduction}

Currently, due to reports which issued to worldwide the Organization for Economic Cooperation and Development (OECD) in 2012, concerning the academic performance of the members countries, is talk too much about low level students in areas related to reading (or reading comprehension), mathematics and science. This makes for agenda item for the country members of this organization, especially those from Latin America. Regarding to Mexico, the evaluation most recently of Program for International Student Assessment (PISA) on math specifically, it ranked at 53 out of 65 OECD countries (Ramos, 2013). Also, the OECD points out in the report of 2012, which the specific case of Mexico, "Mexican students show motivation to learn, but also anxiety toward mathematics."

Actions taken by the government of Mexico were developed at the different levels that integrate it, an example of this, at the federal level in the "Plan Nacional de Desarrollo 2013-2018 (National Development Plan), into the 3.1 strategy called "Developing human potential of Mexicans with quality education" has specific lines of action for dealing with this problem. Also, at the state level The "Plan de Desarrollo Veracruzano 2011-2016" (Veracruz Development Plan) states that: "The entity is located in the twenty-second position in mathematics." Also, show the results of other evaluation mechanisms referring to the test "Quality Testing and Educational Achievement" (Exámenes de la Calidad y el Logro 
Educativos -EXCALE, 2008), which present significant evidence, because it is noted that: One out of two students has insufficiency in handling and understanding of mathematics.

Internally in the institutions, mathematics have taken great relevance, due for the difficulty that represent for they, therefore is a reason for the dropout problem (anxiety) that represents for them. The situation presented in the "Instituto Tecnológico Superior de Tierra Blanca, Veracruz", regarding mathematics in engineering students is worrying, because, the percentages of students failed, we observe that in mathematics courses 202 students are reported in repetition course (semester August-December 2013), however, it is important to note, that the highest percentage of failed students $(36 \%)$ is composed by pupils who failed engineering economy and statistics courses, and whose contents is centered around mathematics courses.

In order to define strategies to be followed for improving the academic achievement of the students towards mathematics, we should identify what is the attitude which assumes the student with their process of teaching and learning, and thus, we may define the latent variables that allow us to know if anxiety is important in its achievement.

There are studies where mathematics has been studied from different areas such as the seminal work of Fennema and Sherman (1976) about the attitude towards mathematics. Subsequently Auzmendi (1992) design the scale to measure attitude towards statistics. Meanwhile Galbraith and Hines (1998) design a scale for measuring confidence towards mathematics and the use of technology; Muñoz and Mato $(2007,2008)$ design the scale that measures the level of math anxiety, all of them are references for this research, which aims to answer the following question

RQ1. What is the set of latent variables that allow us understanding the level of student anxiety towards mathematics?

\section{Theoretical Framework}

To understand the theoretical construct of "anxiety", have been conducted several studies in order to identify structures of latent variables to understand the student's attitude towards mathematics. Interest in mathematics anxiety started with the observations of mathematics teachers in the early 1950s. Therefore, in this research we start the discussion since the seminal work of: Dreger and Aiken (1957), Dutton and Blum (1968), Fennema and Sherman (1976) among others.

In 1957, Dreger and Aiken introduced mathematics anxiety as a new term to describe students' attitudinal difficulties with mathematics. They defined it as "the presence of a syndrome of emotional reactions to arithmetic and mathematics" (p. 344). Aiken and Dreger (1961) also designed a scale with their name and that seeks to measure attitudes towards mathematics, this scale integrates 20 items in four dimensions (affective, anxiety, utility and motivation). Dutton and Blum (1968), who designed the scale that bears his name, which is about feelings towards mathematics. This scale integrates 13 elements such as "work with numbers is fun" and "the arithmetic should be avoided wherever possible".

Another is the scale of attitudes towards mathematics designed by Fennema and Sherman (1976), which integrates 108 items, in nine dimensions distributed in 12 groups with the following subscales:

1) Mathematics success.

2) Mathematics as men's domain.

3) Father's attitude toward math.

4) Mother's attitude toward math.

5) Motivation.

6) Professor's attitude toward math.

7) Anxiety doing math.

8) Confidence in oneself as mathematics student.

9) Math's usefulness.

According to these researches, the sexist environment in the classroom increases math anxiety in students, specifically in girls. Fennema and Sherman (1976) found --in collaboration with a group of students-- that there were differences among the anxiety felt the young people and anxiety felt by children, and that girls, are who suffer most math anxiety. Also identified that if both students - boys and girls - they carried out the same number of math courses, the differences among the levels of math anxiety would disappear and would be the same in boys and girls.

Regarding math anxiety, also was identify a seminal research of Richardson and Suinn (1972) who designed the mathematics anxiety rating scale (MARS) with 98 items and reliability $a=0.89 / 0.96$. Szetela (1973) performed the Debilitating Anxiety scale to mathematics with his name, with a reliability of $a=0.83$. Aiken (1979) published an article that talks about "The enjoyment of mathematics, Mathematics Motivation, Value usefulness of mathematics and fear of mathematics". In the review of literature we can find more comprehensive scales such as the Mathematics Anxiety Rating 
Scale (Richardson \& Suinn,1972), the Anxiety Towards Mathematics Scale (Sandman,1980), and the Mathematics Anxiety Questionnaire (Wigfield \& Meece,1988) were developed. Although the Mathematics Anxiety Rating Scale (MARS; Richardson \& Suinn, 1972) is one of the most extensively used mathematics anxiety instruments, Alexander and Martray (1989) reported two important defects. The first one is that, it is a long assessment instrument (98 items), therefore, timeconsuming to administer and to score. However, the Revised Mathematics Anxiety Rating Scale (RMARS; Alexander \& Martray), developed from the original MARS, has only 25 items.

Recently, as an attempt to develop an abbreviated version of the MARS, Suinn and Winston (2003) carry out a research, in order to know the previous studies that attempted to shorten the original MARS (e.g., Levitt \& Hutton, 1984; Rounds \& Hendel, 1980; Plake \& Parker, 1982; Alexander \& Martray, 1989), from this studies, they generated 30 items from Alexander and Cobb (1984), Alexander and Martray, and Rounds and Hendel. The 30 collected items by Suinn and Winston were subjected to a principal components analysis with oblique rotation, and two factors that emerged accounted for $70.3 \%$ of the total variability in the MARS items. Mathematics Test Anxiety accounted for $59.2 \%$ of the variance, whereas Numerical Anxiety accounted for $11.1 \%$ of the variance. The rules established by Suinn and Winston to include the items on the scale designed by they were that: a) every item will show significant factorial loadings at least one published study, and b) that the item was important in at least two studies consulted (Baloglu and Zelhart 2007).

Later Ashcraft and Kirk (2001) conducted research that speaks about the relationship between working memory, math anxiety and performance. Tapia and Marsh (2004) measured anxiety toward math with the test called "the Attitudes toward Mathematics Inventory" (ATMI) with 49 items and sorting in: confidence, math utility, pleasure, motivation and expectations of parents and teachers, with a reliability $a=0.97$.

Swanson (2006) performed a researching called math anxiety, the main result of this researching was that students show a greater numbers of negative attitudes towards mathematics, when the work is more complex.

Muñoz and Mato (2007) designed and structure a scale to measure math anxiety in high school students with 24 items, with a global Cronbach's alpha of 0.9504 , their instrument was divided into five factors. The first factor, anxiety toward evaluation, refers to the anxiety of the student to be evaluated or test anxiety of math's test anxiety. The second factor, anxiety toward temporality, refers to the anxiety of the students toward time they have to resolve a test or a class exercises. The third factor, anxiety toward understanding math problems regards the fear experienced by students from having to understand math problems. The fourth factor, anxiety toward numbers and math operations, refers to the fear of the student when works with numbers. And finally the fifth factor, math anxiety about real life's situation regards the fear felt by the student to face mathematics in real life. The instrument used proves to have high consistency, all this, according to its reliability. As important fact, it was identified that most the students show anxiety level in evaluating and in the mathematical applications in the real life as well.

In theory, according to these authors, math teachers need to intervene to do positive the experiences of students in their first years of study, although they say that in many occasions the academic success and the condition for any subject not always go hand in hand. There are occasions in which students have negative attitudes toward mathematics, but even so, gets good notes in order to pass the course, this does not mean that later these students does not try to distance themselves as much as they can about math. Also analyze the facilities, the working material for practice, computers, as well as have younger teachers, like more conducive environment to prevent and treat anxiety toward mathematics. This does not mean that most experienced professors are not capable of imparting good classes; the advantage of young teachers is that generally they are more excited about their work and have more patience to students.

Besides, it was identified that students learn easier with the means they are accustomed to use, the electronic media that allow teach in a more didactic way, resulting in consequence, a more positive and less traumatic experience with respect to mathematics, which brings a very low level of anxiety or even close to zero. In other study, Muñoz and Mato (2008) encourage teachers to be innovative with their educational system in order to deal with issues such as attitudes and behavior during learning. They ensure that innovate actions taken by teachers in the teaching-learning process of mathematics help to correct and prevent the negative attitudes toward the subject, because this not only affects students with low performance, but also affects the students with a good performance having a negative attitude toward mathematics.

Alemany and Lara (2010) have designed a questionnaire on attitudes toward mathematics to be applied to students of compulsory secondary education level, which is composed of 37 items, with a reliability $(\alpha=.923)$, which is an acceptable range (>0.70) as reported by DeVellis (1991), as well as Kerlinger and Lee (2002).

Therefore, we may assume that the questionnaire meets the psychometric properties and can be considered as very good tool; however, the authors make clear the worry that referred to Morales (2006) about the sincerity of the students considering that the questionnaire is not anonymous. The most significant findings of their study, lead us to 
believe that the experiences of failure in mathematics by the students in previous years, can be predicted negative attitudes toward mathematics. Through regression analysis, the predictive validity was analyzed. To do this, they correlated the experience the student to suspend or not to suspend the previous math course and attitudes towards this subject. They are based on the Bohner and Wanke (2002) notion, whom point out, that previous experiences are the basis for evaluating the student's attitude, either a positive or negative.

Subsequently, Almany and Lara (2010) conducted an exploratory factorial analysis, and removed 23 items; therefore, the new instrument is made up of seven factors: Behavioral Component, Affective Component, Negative Selfconcept, Positive self-concept, Cognitive Component, Demotivation towards the study of mathematics and Expectations of Achievement. These factors explain $56.860 \%$ of total variance.

Finally, to development this empirical research, we take scale Mato and Muñoz (2007) for field applications. These authors state that "on the cognitive level, strong emotions such as anxiety towards mathematics may block logical reasoning of the student". Therefore, it is important to know the level of anxiety present in the student, in order to prevent as be possible, the low performance toward mathematics by them. The student should be aware of potential it can have in this area, if oneself works to overcome the fear or anxiety toward mathematics, and on the contrary, increased emphasis on the usefulness that may have on the daily lives of individuals.

With the bases exposed previously, we assume:

$\boldsymbol{H}_{1}$ : There is math anxiety in students of "Instituto Tecnológico de Tierra Blanca".

$H_{2}$ : The latent variables: anxiety toward evaluation, anxiety toward temporality, anxiety about understanding mathematical problems, anxiety toward numbers and math operations and real-life math situations anxiety help to measure the level of anxiety of the students toward math.

$H_{3}$ : Anxiety toward mathematics can be explained at least by one factor.

\section{Methodology}

\subsection{Kind of Stud}

It is a non-experimental research, because there is no manipulation of the independent variable, these are observed and analyzed as show in the phenomenon of study. It is cross-sectional, because the application of the instrument for data collection was carried out in a single moment of the study. Is explanatory, because we want to know, is the level of anxiety that is present in the study population, from the scale designed by Muñoz and Mato (2007).

\subsection{Population and sample.}

The population are undergraduate students of first, third, fifth and seventh semester who are enrolled in the semester August- December 2013, from "Instituto Tecnologico Superior de Tierra Blanca, Veracruz" with address in Prolongación Av. Veracruz w/n, corner Héroes de Puebla, Col. Pemex, CP 95180, Tierra Blanca, Veracruz, México. Were surveyed 437 students (census). In table 1 is show the stratification of the population:

Table 1. Population Stratification

\begin{tabular}{cccc}
\hline Semester & Women & Men & Total \\
\hline First & 47 & 74 & 121 \\
Third & 51 & 91 & 142 \\
Fifth & 41 & 44 & 85 \\
Seventh & 40 & 47 & 87 \\
Ninth & 2 & 0 & 2 \\
\hline Totals & $\Sigma=181$ & $\sum=256$ & $\sum=437$ \\
\hline
\end{tabular}

Source: Own

\subsection{Test}

Muñoz and Mato (2007) have designed a scale (test) to measure math anxiety, which is proposed for this study. This test consists of 24 items, integrated in five dimensions, which are detailed in the following table. 
Table 2. Dimensions of Anxiety toward mathematics scale

\begin{tabular}{llc}
\hline \multicolumn{1}{c}{ Code } & \multicolumn{1}{c}{ Dimensions } & Items \\
\hline ANSIEVAL & Anxiety toward evaluation & $1,2,8,10,11,14,15,18,20,22,23$ \\
ANSIETEM & Anxiety toward temporality & $4,6,7,12$ \\
ANSPROBM & Anxiety toward understanding mathematical problems & $5,17,19$ \\
ANSINUOP & Anxiety toward the number and operations & $3,13,16$ \\
AMSIMATV & Anxiety toward real life situations & $9,21,24$ \\
\hline
\end{tabular}

Source: take it from Muñoz and Mato Scale (2007)

A Likert scale is used with values $1=$ means nothing (SN) $2=$ A few times (PV), $3=$ Neutral (Neutral) $4=$ Most times (LMV), 5 = Always Much (SM).

\subsection{Statistical procedure}

For evaluation and interpretation of the data collected, we follow the statistical procedure multivariate of factorial analysis proposed by García-Santillán, Escalera-Chávez and Venegas-Martínez (2013). For this, we established the following criterion: Statistical hypothesis: Ho: $\rho=0$ there is no correlation Hi: $\rho \neq 0$ there is a correlation. The statistical test is $\chi 2$ and the Barlett's test of sphericity KMO (Kaiser-Meyer-Olkin), and aditionally the value of MSA (Measure sample adequacy) for each variable of model. This statistical is asymptotically distributed with $p(p-1) / 2$ freedom degrees, a significance level: $\alpha=0.01, p<0.01$ or $<0.05$ load factorial of 0.70 ; and loads increased to 0.55

In order to measure data obtained, we follow the procedure proposed recently by García-Santillán et al (2013) and obtains the following matrix:

\begin{tabular}{cc}
\hline Students & Variables \\
\hline 1 & X11 X12 ... X1p \\
2 & X21 X22 ...X2p \\
$\ldots$ & $\ldots \ldots$. \\
437 & Xn1 Xn2 ....Xnp \\
\hline
\end{tabular}

Source: own

Where:

$\mathrm{X} 11, \mathrm{X} 12 \ldots . . \mathrm{Xn1}$ is given by the following equation: $\mathrm{X} 1=\mathrm{F} 1 \mathrm{a} 11+\mathrm{a} 12 \mathrm{~F} 2+\ldots \ldots+\mathrm{a} 1 \mathrm{kFk}+\mathrm{u} 1 ; \mathrm{X} 2=\mathrm{F} 1 \mathrm{a} 21+$ $\mathrm{a} 22 \mathrm{~F} 2+\ldots \ldots . \mathrm{a} 2 \mathrm{kFk}+\mathrm{u} 2 \ldots \ldots \ldots \mathrm{Xp}=\mathrm{ap} 1 \mathrm{~F} 1+\mathrm{ap} 2 \mathrm{~F} 2+\ldots \ldots+\mathrm{apkFk}+\mathrm{up}$

Therefore, the expression is as follows:

$\mathrm{X}=\mathrm{Af}+\mathrm{u} \hat{U} \mathrm{X}=\mathrm{FA} \mathrm{A}^{\prime}+\mathrm{U}$

Where:

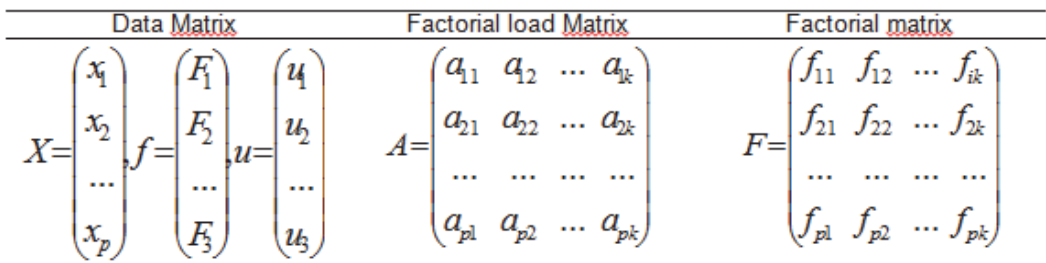

\section{Data Analysis}

The questionnaire was applied to 437 students, mostly from the industrial engineering in different semesters. From field data collected as part of the analysis and interpretation of the instrument was made in the first instance, the reliability test of the instrument, being obtained by the Cronbach's alpha coefficient (AC), which is an index that is used to measure the reliability of the instrument, which allows assessing the internal consistency of scale and assesses whether the 
instrument indicators are correlated. This coefficient is a coefficient of reliability or internal consistency that takes values among 0 and 1 , which helps to check if the instrument is reliable, and can be performed stable and consistent measurements, from the following formula:

$$
\partial=\frac{\mathrm{N} * \bar{r}}{1+(\mathrm{N}-1) * \bar{r}}
$$

Where: $\mathrm{N}=$ Number of items (or latent variables), = it is mean correlation among items.

If the value is closer to 1 , it is more reliable, considering values starting from 0.80 it is a very acceptable value (Hair, 1999; Oviedo and Campos, 2005). Thus, the Cronbach's alpha can be considered as a function of the number of items and the average of correlations among the items. The results of the processed cases are shown in Table 4.

Table No. 4 Statistical reliability.

\begin{tabular}{lccc}
\hline \multicolumn{1}{c}{ Cronbach's Alpha } & N of cases & $\%$ & Alpha \\
\hline Valid Cases & 437 & $100 \%$ & 0.955 \\
Excluded & 0 & & \\
Total & 437 & $100 \%$ & 24 items \\
\multicolumn{1}{c}{ Grouped } & ANSIEVAL & & \\
& ANSIETEM & & 0.815 \\
& ANSICOM & & \\
& ANSINUM & & \\
& ANSISIMA & & 5 dimensions
\end{tabular}

\section{Source: Own.}

The results in the table 4, shows a Cronbach's alpha for all variable of 0.955 (overall) and 0.815 grouped on the 5 dimensions, these values are above 0.7 (Oviedo and Campos, 2005), hence, the group of items that explores a common factor, shows a high value, which indicates that the instrument has the characteristics of consistency and reliability acceptable.

Now we show the results, firstly the main characteristics about population of study, like: gender (figure 1), specialty or career (figure 3) and semester of study (figure 2), and after this, are presented the result from the factorial analysis with extracted components rotated.

Figure 1. Gender

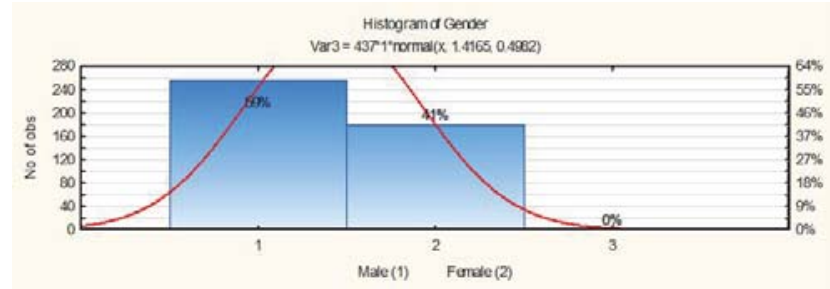

Figure 2. Grade or Semester

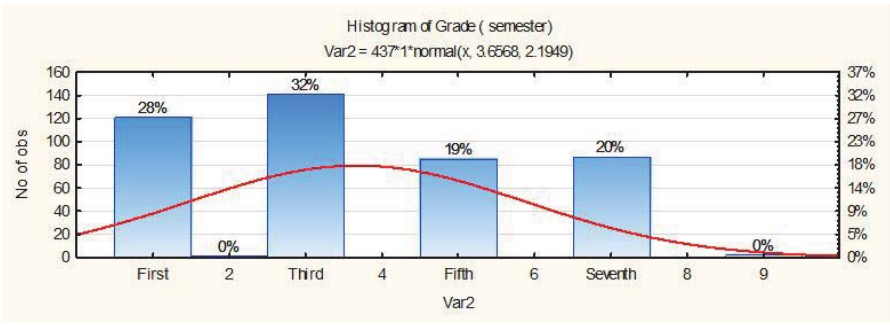


Figure 1. Career or specialty

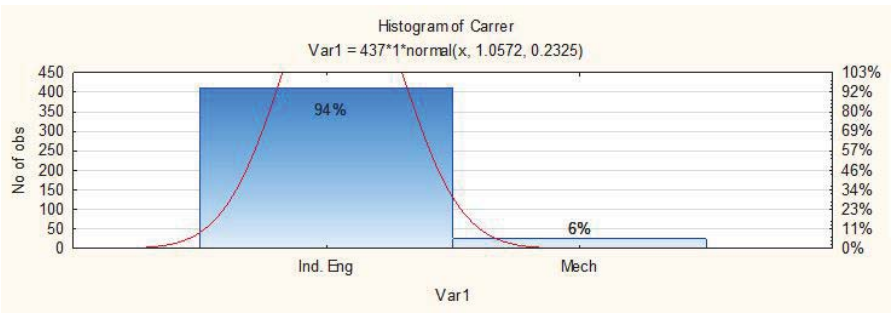

In the above figure about gender, $59 \%$ were male and $41 \%$ female. The semester in which are enrolled students is as follow: 28\% (first semester), 32\% (third semester), 19\% (fifth semester) and 20\% (seventh semester) and finally, 94\% are students' enrolled in Industrial Engineering and the rest 4\% in Mechatronic Engineering. As we can see in the histogram, were applied the instrument to students' of several semesters, being the students' of the third semester (32\%), who mostly answered. The asymmetric bell shaped curve is due to the number of students surveyed in the first and third semesters. Regarding the gender, the most questionnaires were answered by undergraduate students of industrial and mechatronics engineering ( $59 \%$ males).

Within this order of ideas, we can now describe in table 5 , its mean and its standard deviation in order to determine the variance coefficient to identify the variables with the most variance with respect to others.

Table 5: Descriptive Statistics

\begin{tabular}{ccccc}
\hline Factors & Media & Std. Deviation & $\begin{array}{c}\text { No. Cases } \\
\text { Sample }\end{array}$ & Variation coefficient VC=mean/sd \\
\hline ANSIEVAL & 32.8375 & 10.41517 & 437 & 0.317173049 \\
ANSIETEM & 11.6476 & 4.31174 & 437 & 0.370182699 \\
ANSICOM & 7.5011 & 3.13286 & 437 & 0.417653411 \\
ANSINUM & 7.8993 & 3.12197 & 437 & 0.395221096 \\
ANSISIMA & 5.2494 & 2.56646 & 437 & 0.488905399 \\
\hline
\end{tabular}

Source: Own.

As we can see, in the Table No. 5 it shows the necessary descriptive statistics to calculate the coefficient of variation which is a relative measure of variability, useful for comparing the dispersion of populations with significantly different means. This allows identifying the variable that, with respect to the others, has more variation. According to data obtained through a balanced behavior has been noted that the ANSISIMA has greater variability than ANSIEVAL with a $48.89 \%$ and $31.72 \%$ respectively.

Continuing with the data analysis, Ferrando and Anguiano-Carrasco (2010) mentions that factorial analysis is a statistical model that represents the relationship between a set of observable variables (items, subtests or test) each of which can be considered as a criterion to check that this contributes explain the phenomenon studied, therefore, were calculated the Bartlett test of Sphericity, KMO and MSA (Measurement Adequacy of the sample) and $X^{2}$ to justify the use of this technique and the correlation between the variables studied.

Therefore, in Table 6, the results of the Bartlett test of Sphericity, KMO, MSA, $X^{2}$, with significance $(p<0.01)$ are shown.

Table 6: Bartlett test of Sphericity, KMO, MSA, $\mathrm{X}^{2}$, a

\begin{tabular}{ccccc}
\hline Variable & Sig. & MSA & Measure sampling adequacy of Kaiser-Meyer-Olkin KMO & Bartlett test of Sphericity $\left(X^{2}\right)$ \\
\hline ANSIEVAL & 0.00 & .856 & & \\
ANSIETEM & 0.00 & .861 & .881 & 1758.251 \\
ANSICOM & 0.00 & .900 & & df 10 \\
ANSINUM & 0.00 & .888 & & \\
ANSISIMA & 0.00 & .942 & & \\
\hline
\end{tabular}

Source: Own 
In above table, we observed values $X^{2}(1,758.251$ with $10 \mathrm{df})$, which shows that are high, the measure of sampling adequacy (overall) $\mathrm{KMO}(0.881)$ is located in the rank of acceptance because, this should be higher than 0.5 , indicating that the variables are intercorrelated.

The Bartlett test of Sphericity and the KMO compares the magnitudes of the observed correlation coefficients with the magnitudes of the partial correlation coefficients when the KMO $<0.5$ indicates that the cross-correlation index is not large, so the factor analysis is not feasible. Therefore, in table 6 we may observe a KMO value $=0.881$ and a result of $X^{2}$ calculated $=1,758.51$ with $10 \mathrm{df}$ and Sig. 0.00 , which indicate there is significant evidence to reject $H_{0}$, which states that the analyzed variables are uncorrelated. Also, with the results it was verified that the factor analysis is correct to explain the studied phenomenon.

In the Table 7 we can see the results obtained in the anti-image matrix, are two tables showing a covariance matrix anti-image, which contains the negative of the partial covariance and another correlation matrix anti-image containing the partial correlation coefficients with the changed sign. Measures of sampling adequacy for each variable are presented in the diagonal matrix anti-image correlations, which should be close to 1 , therefore, we may observe that the selected factorial model explain the data, because the values in the diagonal range from 0.856 to 0.942 , which are close to 1 , which indicates that the factorial analysis technique is appropriate for measuring the student anxiety toward mathematics, and could be explained by at least one component.

Table 7: Anti-image matrix

\begin{tabular}{llccccc}
\hline & & ANSIEVAL & ANSIETEM & ANSICOM & ANSINUM & ANSISIMA \\
\hline \multirow{5}{*}{ Covarianza anti-imagen } & ANSIEVAL & .219 & & & & \\
& ANSIETEM & -.107 & .225 & & & \\
& ANSICOM & -.060 & -.050 & & & \\
& ANSINUM & -.064 & -.066 & -.085 & & .742 \\
& ANSISIMA & .004 & -.007 & -.084 & -.056 & \\
& ANSIEVAL & $.856 \mathrm{a}$ & & & & \\
& ANSIETEM & -.482 & $.861 \mathrm{a}$ & & & \\
Correlación anti-imagen & ANSICOM & -.240 & -.198 & $.900 \mathrm{a}$ & & \\
& ANSINUM & -.277 & -.282 & -.320 & $.888^{\mathrm{a}}$ & \\
& ANSISIMA & .010 & -.018 & -.183 & -.130 & $.942^{\mathrm{a}}$ \\
\hline
\end{tabular}

Source: Own

From the variables studied, in table 8 are show its correlations, which observe that most of the variables are intercorrelated, because their values are $>0.5$., which suggests that there is a correlation among the set of variables, furthermore, still indicates that factorial analysis is appropriate. Also in the same table we can find at the bottom left the determinant value $(0.017)$ that is less than $<0.05$ which is as close to 0 , indicating that the correlations are significant.

Table 8: Correlation Matrixa

\begin{tabular}{|c|c|c|c|c|c|c|}
\hline & & ANSIEVAL & ANSIETEM & ANSICOM & ANSINUM & ANSISIMA \\
\hline & ANSIEVAL & 1.000 & .850 & .788 & .813 & .427 \\
\hline & ANSIETEM & & 1.000 & .781 & .811 & .432 \\
\hline \multirow{5}{*}{ Correlation } & ANSICOM & & & 1.000 & .798 & .488 \\
\hline & ANSINUM & & & & 1.000 & .474 \\
\hline & ANSISIMA & & & & & 1.000 \\
\hline & ANSIEVAL & & & & & \\
\hline & ANSIETEM & .000 & & & & \\
\hline \multirow[t]{4}{*}{ Sig. (Unilateral) } & ANSICOM & .000 & .000 & & & \\
\hline & ANSINUM & .000 & .000 & .000 & & \\
\hline & ANSISIMA & .000 & .000 & .000 & .000 & \\
\hline & & a. & erminant $=.01$ & & & \\
\hline
\end{tabular}

In the table No. 9 is shown the matrix of components and communalities, where the factors and components are examined, and the value that explains the total variance as well. Moreover, the factor weights obtained by the principal 
extraction components method are also shown.

This values corresponds to each factors that make up component 1 , in this way, we can see that all have a factor > 0.50 , being ANSINUM $(0.919)$ the biggest weight (anxiety towards numerical operations), followed by ANSIEVAL (0.918) and lower factorial weight, but always observing the behavior $>0.5$ is ANSISIMA (0.611). And next to the proportion of variance explained by the communalities, we have ANSINUM (0.844), showing the highest value, and in the extreme opposite we have ANSIMA (0.374) with the lower value.

Table 9. Component Matrix and Variance

\begin{tabular}{|c|c|c|}
\hline Factors & $\begin{array}{l}\text { Component } 1 \\
\text { (load factorial) }\end{array}$ & Communalities \\
\hline ANSIEVAL & .918 & .843 \\
\hline ANSIETEM & .917 & .841 \\
\hline ANSICOM & .907 & .823 \\
\hline ANSINUM & .919 & .844 \\
\hline ANSISIMA & .611 & .374 \\
\hline Eigenvalue & \multirow{2}{*}{\multicolumn{2}{|c|}{$\begin{array}{c}3.725 \\
74.495\end{array}$}} \\
\hline Variance total & & \\
\hline
\end{tabular}

Source: own

Based on the criterion of eigenvalue greater than 1 (3.725) suggests the presence of 1 factor (figure 3), from whose explanatory power may explain the total variance in $74.495 \%$ of total variation in the data. Furthermore, in the same Table 9 factorial weights obtained by the extraction principal components method are shown.

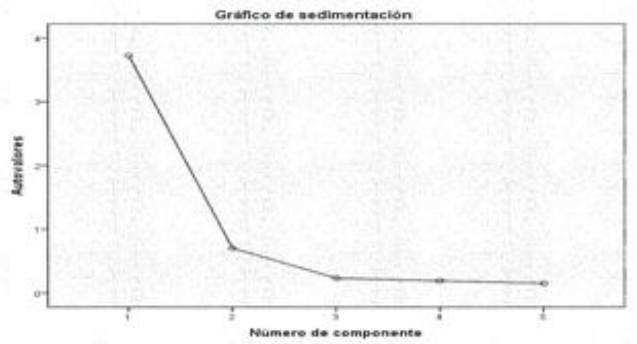

Figure 3: scree plot (source: own)

\section{Discussion}

From the result, sufficient evidence was obtained in order to rejection of the null hypothesis; hence, under the assumption that student in the "Instituto Tecnológico de Tierra Blanca, in Veracruz, México" have anxiety toward mathematics, so it was necessary to use the instrument designed by Muñoz and Mato to get the data, and through statistical analysis, test the hypotheses and answer the question that guides this study.

Therefore, $H_{1}$ is tested, because was obtained evidence that, the student of ITTB shows high level of anxiety towards mathematics, as we can see in table 9 (factorial weights).

Furthermore, $\mathrm{H}_{2}$ is tested, because was obtained evidence about, the latent variables: anxiety toward evaluation, anxiety toward temporality, anxiety about understanding mathematical problems, anxiety toward numbers and math operations and real-life math situations anxiety help to measure the level of anxiety of the students toward math, as we can see in table 9 (total variance $74.495 \%$ is explained).

Finally, $\boldsymbol{H}_{3}$ is tested, because we obtained evidence that we may suppose, that anxiety toward mathematics can be explained at least by one factor, as we can see in table 9 (eigenvalue of one component 3.725, which mean $74.495 \%$ of explained variance). 


\section{Conclusion}

Nowadays the competitive is high; hence, it requires the development of basic competencies for survival, and specific competencies in order to achieve better economic and social development. The OECD sets to member countries that one of these required competencies is mathematical ability, which represents one of the weakest points in developing countries and specifically our country.

There are publications in the field of mathematics from different perspectives or dimensions as: feelings, perception, the use of information technologies and the attitudes, everything about the big problem that represent mathematics for students and for teachers, who have tried to search forms and causes involved in a negative way for learning it.

The national education system has sought to develop models and curricula that achieve reduce the educational problems, about these issues and achieve a competitive advantage or competitive equality.

Regarding the dimensions from the instrument of Muñoz and Mato about: anxiety toward evaluation, anxiety toward temporality, anxiety toward comprehension problems, anxiety toward numbers and math anxiety in real-life situations, we may assume that, when the test is applied in different populations, the result is the same (or similar) as Muñoz and Mato, whoever reaffirms, in the learning-teaching process exists the presence of anxiety toward mathematics in the students, which it is sign of an negative impact for them.

In this work was established that the variable, "anxiety about the numbers" (ANSIENUM) is the factor that most explain the problem, likewise, it is important pay attention to other variables because their values, are very close to each other.

\section{Acknowledges}

The authors are very grateful to the anonymous blind-reviewer for all suggestions, to the Universidad Cristóbal Colón and Instituto Tecnológico de Tierra Blanca, Veracruz for all their help and support.

This research is financed by Universidad Cristobal Colón (Sponsoring information). Furthermore, this research is part of several empirical studies that we carry out in the southeast in Mexico. The aim was to find empirical evidence about anxiety level toward mathematics on different level of study such as: Elementary School, Jr. High School (middle), High School and College/undergraduate.

\section{References}

Aiken, L. \& Dreger, R. (1961). The effect of attitudes on performance in mathematics. Journal of Educational Psycology, $52,19-24$.

Alemany, I. A; Lara, A. I. (2010). Las actitudes hacia las matemáticas en el alumnado de eso: un instrumento para su medición [Attitudes towards mathematics in ESO students: an instrument for measuring]. Publicaciones-40. Pag. 49-72.

Alexander, L., \& Cobb, R. (1984). Identification of the dimensions and predictions of mathematics anxiety among college students. Paper presented at the meeting of the Mid-South Educational Research Association, New Orleans, LA.

Alexander, L., \& Martray, C. (1989). The development of an abbreviated version of the Mathematics Anxiety Rating Scale. Measurement and Evaluation in Counseling and Development, 22, 143-150.

Ashcraft, M; Kirk; E. P.(2001). The Relationships Among Working Memory, Math Anxiety, and Performance. American Psychological Association, Inc. 0096-3445/OI/S5.00 DOI: 10.1037//0096-3445.130.2.224.

Auzmendi, E. (1992). Evaluación de las actitudes hacia la estadística en alumnos universitarios y factores que las determinan. [Evaluation of attitudes towards statistics in college students and factors which determine them] Unpublished doctoral thesis. Universidad de Deusto, Bilbao.

Baloglu, M., and Zelhart, P.F. (2007) Psychometric properties of the revised mathematics Anxiety rating scale. The Psychological Record, 2007, 57, 593-611

Bohner and Wanke (2002), Attitudes and attitude change. New York, NY. Psychology Press.

DeVellis, R. F. (1991). Scale Development: Theory and applications. Applied Social Rssearch Methods Series, vol. 26. Newbury Park: Sage.

Dreger, R. M., \& Aiken, L. R. (1957). The identification of number anxiety in a college population. Journal of Educational Psychology, 48, 344-351.

Dutton, W. H. \& Blum, M. P. (1968). The measurement of attitudes toward arithmetic with a Likert-type test. Elementary School Journal, 68, 259-264.

Escalera-Chávez, M.E., García- Santillán, A. \& Venegas-Martínez, F. (2013). Attitude toward statistics in college students. International Journal of Mathematical Archive. 4(5), 229-234.

Fennema, E. \& Sherman, J. (1976) Fennema-Sherman Mathematics Attitudes Scales: Instruments Designed to Measure Attitudes 
Toward the Learning of Mathematics by Males and Females. JSAS Catalog of Selected Documents in Psychology, 6, 31. (Ms. No. 1225). Journal for Research in Mathematics Education, 7, 324-326.

Ferrando, P.J. \& Anguiano-Carrasco, C. (2010). El análisis factorial como técnica de investigación en psicología [Factorial analysis as a research technique in psychology]. Papeles del Psicólogo. 31(1). 18-33.

Galbraith, P. \& Haines, C. (1998). Disentangling the nexus: Attitudes to mathematics and technology in a computer learning environment. Educational Studies in Mathematics 36, 275-290.

García-Santillán, A.; Escalera-Chávez, M.; and Venegas-Martínez, F.; (2013). Principal components analysis and Factorial analysis to measure latent variables in a quantitative research: A mathematical theoretical approach. Bulletin of Society for Mathematical Service and Standars Vol. 2(3) pp. 03-14,

García-Santillán, A.; Escalera-Chávez, M.; and Venegas-Martínez, F.; (2013). How is perceived the financial mathematics teaching process mediated by ICT: Differs by type of universities? International Journal of Mathematical Archives, Vol. 4(8), pp. 201-209.

Hair, J. F. Anderson, R. E. Tatham, R. L. and Black, W. C. (1998). Multivariate data analysis (Fifth edition. Spain Prentice Hall.

Kerlinger, F. y Lee, H. (2002).Investigación del comportamiento: Métodos de Investigación en Ciencias Sociales. México: McGraw Hill Interamericana.

Morales, P. (2006). Medición de las actitudes en Psicología y Educación. Construcción de cuestionarios y problemas metodológicos (3a Ed.). Madrid: Universidad Pontificia Comillas Ortega Ediciones.

Muñoz-Cantero, J.M.; y Mato, M.D. (2007). Elaboración y estructura factorial de un cuestionario para medir la "ansiedad hacia las matemáticas" en alumnos de educación secundaria obligatoria [Elaboration and factorial structure of an questionnaire to measure math anxiety in students of compulsory secondary education]. Revista Galego-Portuguesa de psicoloxía e educación Vol. 14 No.1, pp. 221-231.

Muñoz-Cantero, J. M.; y Mato, M. D. (2008). Análisis de las actitudes respecto a las matemáticas en alumnos de ESO [Analysis of attitudes about mathematics in ESO students]. Revista de Investigación Educativa, Vol. 26 No.1, pp. 209-226.

Oviedo, H. C; Campos, A. A. (2005). Aproximación al uso del coeficiente alfa de Cronbach's [Approach to the use of Cronbach's alpha coefficient].. Revista Colombiana de Psiquiatría, vol. XXXIV, núm. 4, 2005, pp. 572-580.

Plan Nacional del Desarrollo (2013-2018). [National Development Plan of Mexico]. Secretaria de gobernación. México

Plan Veracruzano de Desarrollo (2011-216) [Develppment Plan of Veracruz]. Gobierno del estado de Veracruz. México.

Plake, B. \& Parker, C. (1982). The development and validation of a revised versión of the Mathematics Anxiety Rating Scale. Education \& Psycological Measurement, 42(2), 551-557.

OCDE (212). Programa para la Evaluación Integral de los alumnos [ ]. Nota País. Resultados

Ramos, G. (2013). Seminario OCDE Con Legisladores Mexicanos. OCDE.

Richardson, F.C., and Suinn, R.M. (1972) The mathematics Anxiety Rating Scale: Psychometric Data", Journal of Counselling Psychology 19, 551-554

Rounds, J. B., \& Hendel, D. D. (1980, March). Measurement and Dimensionality of Mathematics Anxiety. Journal of Counseling Psychology, 27(2), 138-149.

Sandman, R. S. (1980). The mathematics attitude inventory: Instrument and user's manual. Journal for Research in Mathematics Education, 11, 148-149.

Swason, D; Nebraska A. (2006). Math Anxiety. What can teachers do to help their students overcome the feeling?. Math Anxiety. Pag. 129.

Suinn, R. M., \& Winston, E. H. (2003). The Mathematics Anxiety Rating Scale, a brief version: Psychometric data. Psychological Reports, 92, 167-173.

Szetela, W. (1973). The effects of test anxiety and success/failure on mathematics performance in grade eight. Journal for research in Mathematics Education, 4. 152-160.

Tapia, M., \& Marsh II, G. E. (2004). An instrument to measure mathematics attitudes. Academic Exchange Quarterly, 8, $16-21$.

Wigfield, A., \& Meece, J. L. (1988). Math anxiety in elementary and secondary school students. Journal of Educational Psychology, 80 , 210-216. 